\title{
A TEXTUALIZAÇÃO DE VERBETE ENCICLOPÉDICO EM SISTEMAS WIKI
}

\author{
Rossana Aparecida Finau* \\ Universidade Tecnológica Federal do Paraná \\ Departamento de Linguagem e Comunicação \\ Curitiba, PR, Brasil \\ Mateus Lourenço Ribeirete**
}

\begin{abstract}
Resumo: Este artigo visa a analisar a textualização de verbetes de enciclopédias Wiki, a fim de verificar se são resultantes da criação de um novo gênero, uma inovação que gera a emergência de nova espécie - na perspectiva de tipelementos de Travaglia (2007a, 2007b) - ou se mantêm as características tradicionais dos textos impressos. Para tanto, em uma investigação qualitativa, dois verbetes de enciclopédias da Web são comparados desde sua organização de superestrutura até a macroestrutura, tomando como dado mais específico das regularidades linguísticas a ocorrência de modalizadores em verbetes. A análise parte de um foco mais geral, seguindo a orientação de Araújo (2016) para análise de reelaboração de gêneros em meios digitais, verificando o contexto de formação do gênero. Observa-se que não há diferenças suficientes entre a textualização dos exemplares a ponto de defender o surgimento de um novo gênero de verbete por ser apresentado de modo digital.
\end{abstract}

Palavras-chave: Tecnologia. Hipertexto. Wiki. Verbete. Tipelementos.

\section{INTRODUÇÃO}

Desde a popularização da Wikipedia, na primeira década do século XXI, as páginas colaborativas se difundiram amplamente pela internet - não é preciso muito esforço para encontrar enciclopédias dedicadas aos mais variados assuntos. Do Wikitravel, cujo foco recai no auxílio a viajantes, a diversos sites que encapsulam informações sobre franquias intermidiáticas (Star Wars, Harry Potter, Pokémon etc.), a organização de páginas que se valem do Software Wiki se firmou na cultura digital contemporânea. Outra evidência desse crescimento pode ser representada pela existência de enciclopédias satíricas, como a Desciclopédia, pois seu humor se concretiza a partir de um referencial já conhecido. Em comum, têm gratuidade e edição coletiva pelos usuários, com possíveis intervenções de administradores.

Entre as várias enciclopédias espalhadas pela rede digital, duas chamam a atenção pela discrepância: Conservapedia e RationalWiki. A primeira se define como conservadora e cristã, favorável à constituição de família nos moldes das religiões tradicionais no contexto do cristianismo. Em relação à popularidade da Conservapedia,

\footnotetext{
* Doutora em Estudos Linguísticos pela Universidade Federal do Paraná (UFPR). Professora da Universidade Tecnológica Federal do Paraná (UTFPR). E-mail: rossana@utfpr.edu.br.

*** Mestre em Linguagem e Tecnologia pela Universidade Tecnológica Federal do Paraná (UTFPR), 2017. Revisor de texto na empresa Audiotext. Curitiba, PR. E-mail: mribeirete@ gmail.com.
} 
são cerca de 42 mil artigos divididos em mais de 500 milhões de visualizações. Por sua vez, a RationalWiki se explica como um projeto que visa à exploração de assuntos científicos, refutando pseudociências e fundamentalismo com base no ceticismo racional. Essa enciclopédia, criada como contraponto à Conservapedia, abriga mais de seis mil artigos, quase todos em inglês - há versões pouco expandidas em russo, francês, espanhol e português. Ambas também se ocupam de análises midiáticas acerca de seus temas.

Do contraste entre esses dois posicionamentos, extrai-se o ponto de partida deste artigo: diante de comunidades discursivas tão diferentes, encontrar o que há em comum entre suas enciclopédias revelará padrões concretos sobre o gênero verbete enciclopédico elaborado coletivamente com o uso de sistema Wiki. Esses textos são criação de gêneros novos, inovações do mesmo gênero com a emergência de espécies de verbete ou, simplesmente, o mesmo gênero verbete anterior às plataformas digitais? A ideia de tomar duas enciclopédias com objetivos contrários tem como propósito justamente verificar se a estrutura linguística difere ou não. Afinal, se dois sites radicalmente opostos propõem verbetes sobre os mesmos temas, presume-se que haja considerações reveladoras a respeito tanto da organização das próprias enciclopédias nos sistemas Wiki, quanto sobre os gêneros nelas desenvolvidos. E, justamente, o contraste entre os respectivos conteúdos pode permitir uma análise mais clara dessas estruturas organizacionais. Para o desenvolvimento desse objetivo, faz-se necessário descrever a organização de enciclopédias que se valem do sistema Wiki e detalhar seu contexto de desenvolvimento, bem como buscar, na linguística, o devido referencial para separar o que será tratado como gênero daquilo a ser interpretado como suporte. Assim, as enciclopédias serão comparadas em seu design geral - diagramação, funções básicas, página inicial - para, então, a análise de artigos específicos ser executada. Nesse ponto, tendo como foco a estrutura dos verbetes, considerações específicas sobre a linguagem empregada também serão exploradas - por exemplo, o uso de modalizadores. A escolha dos modalizadores como elemento linguístico a ser avaliado nos verbetes se dá pelo fato de essa espécie de gênero ter como função ou objetivo sociocomunicativo original apresentar de modo informativo conceitos estabelecidos em algum paradigma acadêmico-científico, sem transpor tal informação para o nível argumentativo, por exemplo, discutindo polêmicas referentes a categorias teóricas. Esse objetivo, de certo modo, já oferece ao produtor do verbete recursos de textualização afinados para a situação discursiva mais informativa do que argumentativa; então, inversamente, os modalizadores - como recursos linguísticos empregados tanto para entrever posicionamentos sociais defendidos como para relativizar tais posicionamentos - podem dar pistas sobre a possibilidade de a função do gênero passar por alteração. Ou seja, pela análise dos modalizadores, é possível observar se há intervenção na reelaboração interna do verbete, visto que a constituição lexical e gramatical do texto, isto é, o processo de textualização, na perspectiva aqui defendida, é, também, produção e produto de normas sociais de atuação.

\section{SOBRE AS ENCICLOPÉDIAS E SEUS VERBETES}

Para analisar a organização de verbetes em Wikis, é preciso comentar sobre dicionários e enciclopédias, os suportes - em meios digitais ou analógicos - em que esses 
textos ocorrem. O dicionário não será destacado neste trabalho, visto que serão comparados apenas verbetes de Conservapedia e RationalWiki, que são enciclopédias, as quais, de acordo com a Wikipedia, apresentam uma coletânea de textos cujo objetivo principal é descrever o melhor possível o estado atual do conhecimento humano tanto nas ciências como nas artes. Elas podem ter o formato de livro ou de página na internet. Com relação à seleção de conteúdo, podem ser genéricas como a Wikipedia e a Britannica, ou especializadas, com temáticas específicas, como as obras aqui analisadas. Essas coletâneas podem apresentar gêneros textuais diversos, como mapas, tabelas, gráficos, os quais geralmente complementam o verbete, gênero de maior ocorrência. A primeira enciclopédia, Encyclopédie, foi idealizada e editada pelo filósofo e escritor francês Denis Diderot (1713-1784), com a colaboração do físico e matemático Jean d'Alembert (17171783), mas os 35 volumes foram escritos por um coletivo de autores anônimos que traziam informações para os organizadores da obra e, também, por especialistas nas mais diversas disciplinas, como: Montesquieu, Voltaire, Rousseau, Buffon, Quesnay, Grimm. Ou seja, a enciclopédia é o suporte do gênero verbete. Uma das questões que se pode formular sobre isso é se o formato impresso/analógico ou digital/on-line de uma enciclopédia pode alterar a organização linguística dos gêneros que a compõem, por exemplo, no que diz respeito às superestruturas textuais/discursivas. Esse ponto será discutido adiante para a análise de verbete produzido na World Wide Web, em Wikis.

Com relação a descrições específicas sobre o gênero verbete enciclopédico, para além da definição mais geral encontrada em diferentes dicionários, como conjunto de acepções, exemplos e outras informações pertinentes contido numa entrada de enciclopédia, há o trabalho de Dionísio (2005), no qual se propõe que verbete é composto por significados independentes entre si, isto é, os enunciados que formam a explicação de um verbete não têm necessariamente sequencialidade, não formam uma prosa contínua, podendo ser usados em separado. Os verbetes, mesmo os analógicos, conforme a pesquisadora, não têm identificado o seu autor ou autores, pois são escritos pelo conjunto de autores da enciclopédia. Dionísio (2005) lembra que a apresentação dos verbetes tradicionais se dá pela ordem alfabética.

Sobre os verbetes da Wikipedia, mais especificamente, valendo-se da teoria sobre gêneros do discurso de Miller (1994), Lima (2009) os descreve como textos que podem ser acrescentados, removidos ou alterados constantemente pelos colaboradores na construção da enciclopédia, e essa, para a autora, seria uma diferença entre esses verbetes e os tradicionais, pois esses últimos não são revistos em um curto período de tempo, e assim são mais estáticos do que aqueles. Outra diferença apontada pela autora é o fato de os verbetes da Wikipedia não serem apresentados por uma sequência alfabética, numérica ou temporal, pois a busca do leitor se dá por palavras-chave, e o sistema utiliza a estratégia de scanning para encontrar o verbete procurado. A pesquisadora também observa a presença de links no texto de modo a formar numa rede de informação interconectada.

A questão que se coloca aqui é se essas condições de produção apontadas pela autora e os dois itens diferentes na constituição da superestrutura - o sistema de busca e o emprego de hiperlinks - são motivos suficientes para que tenham ocorrido alterações na organização linguística do verbete enciclopédico apresentado em uma Wiki. A fim de investigar essas questões, este trabalho analisará verbetes de duas enciclopédias que, 
assim como a Wikipedia, são organizadas por software Wiki, ou seja, de modo colaborativo e com recursos de hiperlink, mas a partir do ponto de vista teórico desenhado por Travaglia (2007a, 2007b), com a proposta de analisar a formação de gêneros textuais sob o foco de três categorias, os tipelementos. Esta tarefa inicia agora.

\section{GÊNEROS TEXTUAIS: TRAVAGLIA E ARAÚJO}

Nesta investigação, para verificar se a organização linguística do gênero verbete produzido para atender a estrutura Wiki é uma produção nova, a mesma de verbetes de enciclopédias analógicas ou uma subclasse desses, será considerada a caracterização de textos a partir das categorias de tipelementos. Conforme Travaglia (2007a, p. 41), é possível caracterizar textos observando três categorias diferentes, chamando-as de tipelementos, isto é, "classes de categorias de texto de uma dada natureza", sendo elas o tipo, o gênero e a espécie. Enquanto o tipo se refere ao modo de interação, interlocução - por exemplo, dissertativo ou injuntivo, literário e não literário -, a categoria gênero desempenha "uma função sociocomunicativa específica" (2007a, p. 41). Por sua vez, a espécie se vale dos traços formais da estrutura, da superfície linguística, incluindo a superestrutura, bem como o conteúdo.

Vale ressaltar que a categoria espécie, de acordo com Travaglia (2007b), também se relaciona com a forma, a qual orienta a organização textual em termos de superestrutura composicional - como em um artigo científico, cuja forma esquemática culturalmente convencionada inclui o preenchimento de estruturas vazadas com conteúdo de Título, Resumo, Abstract etc. Conforme o autor, as superestruturas funcionam como referências para a construção dos textos orais e escritos nas línguas. Tendo em vista particularidade de a categoria espécie dizer respeito tanto aos elementos da superfície textual quanto ao conteúdo, neste trabalho propõe-se que nela estão abarcados elementos de super e macroestruturas, seguindo, neste caso, Van Dijk e Kintsch (1983), que descrevem macroestrutura como unidade semântica em que os vários aspectos da significação são materializados por meio de categorias lexicais, sintáticas, semânticas e estruturais. Ou seja, o todo semântico de um texto é dado pela relação entre unidades menores ou subunidades de sentido, então modalizadores, por exemplo, fazem parte do estabelecimento da leitura geral do texto.

É preciso salientar a natureza multifacetada das categorias tipo, gênero e espécie. Para isso, destaca-se a explicação de Travaglia (2007a, p. 41): “A narração é um 'tipo', enquanto romance, conto, novela, fábula, parábola, apólogo, mito, lenda, caso, fofoca, notícia, ata, biografia etc. são 'gêneros'. Tipos e espécies compõem os gêneros: tipelementos que existem e circulam na sociedade."

Para o autor, o gênero pode ser reconhecido por exercer uma função sociocomunicativa específica, isto é, o discurso que existe e circula na sociedade, ao passo que tipos e espécies não ocorrem a não ser quando realizados em um gênero. Para o pesquisador, as espécies podem estar vinculadas a tipos ou a gêneros. Alguns gêneros podem depender de tipos, como o exemplo dado pelo autor com o gênero tese, composto pelo tipo dissertativo como dominante, mas que pode apresentar outros, como descrição. 
Também há gêneros organizados por vários tipos - desprovidos de um dominante -, como a carta, que não requer nenhum tipo específico. Esse parece ser justamente o caso do verbete enciclopédico de Wiki, pois nele há indicações de uma fusão de características, conforme a análise a ser feita na seção 4 deste artigo.

São relevantes também as considerações de Araújo (2016). Para o autor, que toma os pressupostos de Bakhtin (2011 [1972]), não existem esfera digital ou gêneros digitais, visto que a Web não seria uma esfera discursiva ou de comunicação (cotidiana, acadêmica, jurídica...) na qual tipos relativamente estáveis de enunciados são elaborados, mas simplesmente, como rádio e televisão, a Web é mais um ambiente onde são abrigados discursos e seus gêneros, ou seja: não existe gênero digital na esfera digital. Por isso, Araújo (2016), tomando como alicerce as propostas de Costa (2010), defende que se investigue a possibilidade de haver processo de reelaboração de gêneros que emergem das relações entre linguagem e tecnologia, pois o indivíduo, ao se apropriar desta última, altera suas formas de interação.

O fenômeno de atualização de gênero, de acordo com o autor, poderia ser resultado da existência de um continuum no processo de reelaboração criadora entre gêneros estandardizados (mais próximos dos originais) e emergentes (novidades). Estes últimos, ao contrário dos estandardizados, teriam atualizações mais complexas envolvidas na sua produção, pois envolveriam maior grau de ineditismo e duas possibilidades de organização: interna e externa. Na primeira seriam classificados os gêneros atualizados na Web sem a mesclagem de outros gêneros; na segunda, externa, por outro lado, ocorreria a remix (intervenção hibrida mínima, mantendo-se próxima ao original) e a mashups (quando há mesclagem ao máximo, com combinações e colagens de diferentes matrizes). Importante ressaltar que, para Araújo (2016), em vista da dinâmica de interação social dada pela mídia Web, nos dois modos de atualização de gêneros a mobilização do propósito comunicativo surge como elemento fundamental.

No que tange à perspectiva de Travaglia (2007a, 2007b), sendo os tipelementos multifacetados e a categoria espécie responsável pela organização de características de super e macroestruturas, é possível supor que tais características possam interferir na formação dos gêneros e suas funções sociocomunicativas. Devido a essa hipótese, na análise proposta são avaliados elementos formais nos dois níveis de textualização: super e macroestrutural. Embora espécie se defina por aspectos formais de estrutura, da superfície linguística e/ou conteúdo, Travaglia (2007a, p. 62) afirma que essa categoria "sempre incorpora o(s) objetivo(s)/função(ções) dos tipos e gêneros a que se ligam". O autor ainda explica que os gêneros são definidos por sua função sociocomunicativa, mas os tipos também apresentam objetivos, como um ato ou macroato de fala. Ou seja, a função sociocomunicativa se apresenta como um fator importante na caracterização multifacetada dos tipelementos, tanto que o pesquisador a elenca como o terceiro parâmetro para caracterizar as categorias de texto. Isso porque, na proposta de Travaglia (2007a, 2007b), o objetivo comunicativo gera no produtor do texto uma perspectiva que o leva a uma antecipação no dizer. Essa perspectiva produz um tipo de texto: descrição, dissertação, injunção, narração, argumentativo stricto sensu e não argumentativo stricto sensu. Ainda, explica Travaglia (2007a, p. 51): "o objetivo/função pode variar conforme a época e, neste caso, mudaria a caracterização do gênero". 
Então, em uma proposta de categorias de tipelementos multifacetadas, é possível considerar, por exemplo, que elementos lexicais que atuam na constituição semântica da macroestrutura, na categoria espécie textuais, podem auxiliar a denotar a função comunicativa de gênero. E, ainda, que alterações no uso desses recursos poderiam mostrar mudanças no próprio gênero. A partir dessas considerações, a fim de analisar a textualização de verbete de enciclopédias sustentadas por software Wiki e verificar se eles são resultantes da criação de um novo gênero ou uma inovação que leva à emergência de espécie nova do gênero, este trabalho tomará a modalização como elemento de macroestrutura, para avaliar se houve mudança de função comunicativa, a qual pode estar relacionada tanto a espécie, quanto a tipo, na formação geral de gênero.

Entre as categorias lexicais, unidades menores, que atuam na macroestrutura textual para estabelecer coerência textual, estão os modalizadores. Por serem, como já afirmado, recursos linguísticos que permitem entrever pontos de vista particulares, deveriam ser evitados na textualização de verbetes, pois, de acordo com Marcuschi (2010), tais gêneros precisam refletir certa posição de neutralidade. Então, os modalizadores podem indicar se a função sociocomunicativa do gênero verbete, compreendida também na macroestrutura textual, está passando ou não por alteração. Sob o enfoque dos tipelementos, a modalização pode apontar se, na organização desses textos, há ou não diferenças que sustentem a hipótese de todos pertencerem ao mesmo gênero, como espécies distintas, de serem o mesmo gênero ou uma nova espécie, visto que função é fator importante para a categorização de espécie, tipo e gênero como defendido anteriormente.

Por meio da linguagem, os falantes atuam nos processos de interlocução de modo a atenderem seus objetivos de comunicação. Para isso, o produtor de textos (visando a adequar sua produção às suas intenções sociais, culturais e históricas) mobiliza recursos linguísticos e expressivos para organizar sua argumentação. Ao mobilizar tais recursos, que são variados na língua - como adjetivos, advérbios, operadores lógicos e até a própria entonação -, o autor, ao mesmo tempo em que intenciona adequar seu texto a um objetivo comunicativo, acaba por deixar pistas sobre o seu ponto de vista a respeito do que é dito. A linguística tem denominado esse conjunto recursos; quando recortados para serem analisados como indicadores de força argumentativa, como modalizadores. Os modalizadores têm sido estudados, principalmente, pelos campos de Semiótica, Análise do Discurso, Linguística Textual, Semântica e Pragmática. Para este trabalho, a abordagem das duas últimas áreas é a escolhida, a partir dos estudos de Castilho e Castilho (1993) e Castilho (2010).

Castilho e Castilho (1993), ao estudarem advérbios modalizadores, explicam que esses elementos denotam um julgamento do falante perante a proposição, ou seja, ao selecionar um recurso modalizador em função da força argumentativa que se pretende alcançar, é o locutor que expressa e realiza uma avaliação, deixando pistas na estrutura linguística para orientar a forma como quer seu discurso seja lido pelo interlocutor. No caso da pesquisa desses autores, os modalizadores adverbais são recursos valiosos para denotar o ponto de vista do produtor de texto sobre o conteúdo de sua proposição ao recorrer a eles para reforçar suas afirmações, negações, ordens, permissões, certezas, dúvidas ou distanciamentos. Vale destacar que os advérbios modalizadores estendem seu 
escopo semântico às sentenças como um todo e não apenas a um sintagma verbal, principalmente quando estão na posição mais à direita da oração; assim, eles operam sobre o conteúdo proposicional ou sobre a asserção de que é objeto.

Castilho (2010) classifica os modalizadores em três conjuntos, a depender do valor semântico e pragmático que expressam. O primeiro contém os epistêmicos, que denotam juízo de valor, uma avaliação do locutor sobre o dito, sua proposição como verdadeira tanto ao negá-la quanto ao afirmá-la. São exemplos desses elementos: realmente, com certeza, evidentemente, absolutamente, inegavelmente, exato, lógico, de forma alguma, de jeito nenhum, entre outros. O segundo conjunto descrito de modalizadores diz respeito aos deônticos, os quais expressam dever ou obrigação; por exemplo, os verbos ter, querer, poder, dever, ordenar, determinar, permitir, etc. O terceiro conjunto abriga modalizadores discursivos, isto é, os recursos linguísticos que deixam entrever, por parte do locutor, os sentimentos, as emoções ou as relações intersubjetivas entre os interlocutores. São exemplos desse último conjunto recursos como: felizmente, infelizmente, espantosamente, sinceramente, lamentavelmente etc.

Mesmo breve, essa explicação sobre o uso de modalizadores permite ampliar o olhar para a textualização dos verbetes alocados em enciclopédias Wiki, tendo mais um ponto da organização linguística desses textos como referência para análise dos tipelementos de Travaglia (2007a, 2007b). Isso porque, conforme o proposto aqui, tipo pode ser identificado e caracterizado por instaurar um modo de interação e uma maneira de interlocução, podendo variar no gênero conforme o objetivo comunicativo. Tipos ainda podem estar entrelaçados com espécies, cuja organização macroestrutural também tem a possibilidade de entrar em cena para a percepção da função comunicativa, ou seja, para o reconhecimento do gênero. Assim, a averiguação de ocorrências de modalizadores pode ser chave para descrição das tipologias e espécies que sustentam os gêneros, inclusive para avaliar se verbetes em softwares Wiki são um gênero próprio, uma espécie de verbete ou, ainda, apenas verbete tradicional. Para observarmos isso, segue a análise.

\section{ANÁLISE: A QUESTÃO DO GÊNERO WIKIS E HIPERTEXTO}

A realização do estudo foi determinada por uma sequência de procedimentos metodológicos a partir do ponto de vista da pesquisa qualitativa, visto que os dados coletados foram interpretados, analisados e descritos de modo comparativo em uma perspectiva integrada, isto é, considerando o fenômeno da organização do gênero verbete em suas nuanças textuais e contextuais. Ainda para a comparação dos dados, buscou-se referencial teórico sobre descrições já existentes a respeito da produção de verbetes enciclopédicos tradicionais, bem como a formação dos gêneros discursivos e os processos de modalização na linguagem. A amostragem aqui é probabilística, por ser a pesquisa ainda inicial e exploratória.

Sob esse olhar é que estão apresentados os dados deste artigo e sobre a seleção deles é necessária uma ressalva. Como as enciclopédias foram escolhidas por apresentarem pontos de vista opostos, a fim de sustentarem mais claramente uma análise de comparação entre seus verbetes, as versões em língua portuguesa precisaram ser descartadas, visto 
que ainda não têm representatividade suficiente entre os internautas/colaboradores - basta ver a ínfima quantidade de material elaborado em seus bancos de dados. Assim, as versões inglesas da Conservapedia e da RationalWiki foram preferidas para análise. Diante do ponto de vista da teoria linguística, na verdade, isso não se apresenta como um problema, pois como os verbetes fazem parte das interações sociais letradas de diferentes comunidades, com a mesma função sociocomunicativa, independentemente da língua compartilhada, o estudo das configurações linguísticas desse gênero textual permite para o inglês ou para o português - que se verifiquem, sob o mesmo enfoque teórico, as construções de sentidos, os temas e a estrutura global do texto, bem como fatos da macroestrutura.

Ao observar os dados, isto é, os verbetes de Conservapedia e RationalWiki, primeiramente na sua organização geral, pode-se pensar que são elaborados de modo totalmente distinto daqueles de enciclopédias tradicionais analógicas, justamente por serem hospedados em enciclopédias apresentadas por um software organizador de informações em páginas da Web: o Wiki. Então, o primeiro procedimento de pesquisa precisou ser o de verificar o funcionamento desse software e as características que ele define para suas páginas, uma vez que isso pode, entre outras coisas, alterar a superestrutura do verbete. Poder-se-ia hipotetizar, por exemplo, como em Lima (2016) e Xavier (2010), que o emprego de hiperlink nesses casos já indica alteração na estrutura dos verbetes aqui investigados. Para observar melhor esse ponto, vale considerar a estruturação dada pelo sistema Wiki às páginas Conservapedia e RationalWiki.

Wiki, do havaiano "veloz", é definido como "um site que pode ser modificado ou incrementado por seus usuários" (DENNIS, 2016, p. 1), ao que se acrescenta aqui, para preencher qualquer vagueza, a condição de que pode ser modificado diretamente por seus usuários. Para que um site funcione dessa forma, no entanto, o processo não é tão puro e simples, ou assim não o foi até a criação do software Wiki, desenvolvido em 1994 pelo programador Ward Cunningham; o software, pois, permite a edição de uma página diretamente do navegador, sem recursos adicionais.

O ano de 2001 foi fundamental para o desenvolvimento das páginas colaborativas, pois, enquanto Cunningham publicava, com Bo Leuf, o livro The Wiki Way, um guia para instalar e utilizar o software Wiki, a Wikipedia saía do papel ao ser fundada por Jimmy Wales e Larry Sanger. Esse projeto levava adiante o que ambos haviam começado com a Nupedia, outra enciclopédia colaborativa, porém desprovida do software Wiki. Qualquer pessoa que tenha utilizado a Wikipedia na última década já se deparou com a onipresença - e o acervo - do site em questão. Somente sua parte anglófona, por exemplo, contém quase 5 milhões de artigos. De acordo com o New York Times (COHEN, 2014), em todas as línguas da enciclopédia (mais de 200), o número mensal de acessos beira os 18 bilhões, o que qualifica a plataforma como uma das mais visitadas de toda a internet. Até o momento, são 291 línguas utilizadas pela Wikipedia, que mantém versões em Guarani e Aimará. Entre os fatores que a levaram à consagração na era digital estão a gratuidade do serviço e a praticidade da edição, impulsionada pelo sistema Wiki, o qual permite realizar edição no próprio navegador. Sua influência foi tão notável que a Encyclopaedia Britannica, uma das mais prestigiadas enciclopédias da história, descontinuou a versão impressa em prol de sua contraparte online (McCarthy, 2012). 
Além disso, surgiram enciclopédias temáticas, como as que servem de objeto para este artigo. Apropriando-se do design geral da Wikipedia, sustentado pelo software Wiki - aberto e replicável sem consequências jurídicas - elas têm se espalhado pela rede, sintoma de que a utilização do software por si só vem formando raízes na internet. $\mathrm{Na}$ base de tudo isso, figura ainda a navegação por meio de hiperlinks, um fator de suma importância para a fluidez dessas páginas. Embora a referenciação por links sempre tenha feito parte da organização da informação em rede nas enciclopédias, com indicações dentro dos verbetes (por exemplo, orientando para outros significados da palavra buscada ou páginas em que ela aparece relacionada a outros temas...), obviamente um sistema de busca automática pode ajudar o leitor a encontrar as repostas que procura, otimizando, inclusive, o uso de espaço para relacionar e atualizar centenas de livros, notícias e artigos nas referências de cada verbete. Basta conferir as subdivisões de que um artigo desenvolvido dispõe: a página "Segunda Guerra Mundial", por exemplo, aponta para páginas autônomas, porém relacionadas, como "Cronologia da Segunda Guerra Mundial", "Causas da Segunda Guerra Mundial" e "Dia da Vitória na Europa", entre várias outras. Essas redes também se formam com os verbetes das enciclopédias analógicas - o que muda é a quantidade de dados que o sistema automático tem à disposição para a busca, a qual é muito mais rápida do que o próprio leitor revirando as páginas indicadas nos verbetes impressos.

Em uma plataforma colaborativa, "a arquitetura do hipertexto optimiza tecnicamente este espaço de livre exposição, construção e debate de múltiplos discursos" (XAVIER, 2010, p. 220). O autor ainda afirma sobre esse assunto que, atrelado à natureza colaborativa da Wikipedia, o hipertexto tem evidenciada a sua condição de lugar de coprodução dos sentidos. Sendo a leitura hipertextual não a exceção, mas o padrão do artigo enciclopédico digital, a textualização realizada por hiperlinks aumenta a intertextualidade e possibilita sincronicidade de interações virtuais - vide Marcuschi (2010). Sobre isso, Xavier (2010) aponta características sinestésicas e deslinearizadas ao hipertexto, com o qual o leitor adquire maior grau de emancipação; porém, o autor destaca que ele pode se ver perdido na quantidade massiva de informações. Este trabalho concorda com essas proposições de Xavier, mas observa, de modo distinto, que essa organização de informações em rede também subjaz à estruturação das enciclopédias analógicas, com menor intensidade de busca e banco de dados, mas com a mesma exigência de certa maturidade do leitor para aplicar habilidades e estratégias a fim de atribuir sentidos mais coesos e coerentes aos textos com esse formato.

Diante dessa configuração das enciclopédias, então, principalmente as de natureza colaborativa, cuja tessitura se dá também pela aplicabilidade de hiperlinks, é preciso retomar a discussão sobre gêneros textuais, considerando esses pontos. A partir dessa condição, algumas opções são possíveis para caracterizar o verbete produzido para Wiki: 1) encarar esse verbete como gênero das enciclopédias tradicionais; 2) como uma espécie do gênero verbete enciclopédico em meio digital; 3) considerar o verbete de enciclopédia digital como gênero novo e próprio.

Na primeira opção, uma página interna, seja "Guerra das Malvinas" ou "Miguel de Cervantes", seguiria a mesma linha de um verbete publicado, por exemplo, na Encyclopaedia Britannica, uma enciclopédia digital desprovida da plataforma Wiki e, 
portanto, não editável pelos próprios usuários. Nesse caso, independentemente da escrita colaborativa ou da premissa digital, o gênero verbete pode ser considerado apresentando a mesma organização tradicional. Essa hipótese não é de todo impossível, basta lembrar que desde a primeira enciclopédia produzida, como mostra Dionísio (2005), vários atores anônimos participaram da seleção e elaboração dos verbetes; o único ponto que se identifica como realmente diferente seria o que registrou Lima (2016), ou seja, o tempo de publicação e alteração entre as obras analógicas e as digitais. Mas esse fator não parece gerar diferença de organização linguística nem na superestrutura nem na macroestrutura do verbete Wiki, visto que uma versão impressa dele, ainda que inferior a seu potencial de navegação instantânea por hiperlinks, não anula sua condição de verbete enciclopédico.

Com relação à segunda hipótese, a anterior também é válida, então, para distinguir a proposta de verbete sem alteração de textualização da que pode considerá-lo como espécie do gênero geral "verbete"; é preciso recorrer ao trabalho de Travaglia (2007b), no qual o pesquisador defende que uma espécie de um gênero só seria viável se apresentasse diferença no valor global da perspectiva sociocomunicativa, isto é, que se percebesse, na sua superestrutura, alteração de sua função/objetivo e temáticas. Não parece ser esse o caso aqui: embora Conservapedia e RationalWiki tenham temáticas opostas, a função sociocomunicativa de seus verbetes continua sendo o de explicar um conceito com padrões sistemáticos. Além disso, mantém o que Dionísio (2005) apontou sobre verbetes tradicionais: significados independentes entre si, não obrigação de sequencialidade, não formam uma prosa contínua. Então, analisando a superestrutura, parece que a primeira hipótese é mais plausível do que a segunda, isto é: o verbete digital é o mesmo tradicional.

Já se apresenta também, por esses dois argumentos para as hipóteses um e dois, que tomar a colaboração anônima ou a existência de hiperlinks para defender o surgimento de um novo gênero, o verbete digital, não parece se sustentar. Mais, ainda que o meio digital e condições tecnológicas tenham sido essenciais para o desenvolvimento do software (e, consequentemente, de qualquer site) Wiki, isso não anula a condição do verbete em wiki como, afinal, um verbete acima de qualquer outro fator (outros elementos que justificam essa proposta serão explorados na análise dos modalizadores). Conforme aponta Marcuschi (2010, p. 31), o hipertexto "não pode ser tratado como um gênero e sim como um modo de produção textual que pode estender-se a todos os gêneros dando-lhes neste caso algumas prioridades específicas”. Pensando assim, verbetes de enciclopédias Wiki não têm sua essência estrutural alterada em relação aos seus correspondentes analógicos apenas por apresentar hiperlinks, visto que esses podem ser considerados como parte da organização dos tipos que podem sustentar diferentes gêneros. Destaque-se que hiperlink nem seria um tipo essencial para textualização dos verbetes de páginas Wiki, pois, considerando a proposta de Travaglia (2007a, 2007b), o gênero não poderia aparecer sem seu tipo essencial, e esse não é o caso dos verbetes aqui analisados.

Assim, a partir dessa argumentação, a análise se faz na tentativa de comprovar que, com base em verbetes da Conservapedia e da RationalWiki, não há produção de gênero novo na textualização dos verbetes desses sites. 


\subsection{DESIGN GRÁFICO: MODELOS TEXTUAIS GLOBAIS}

Para continuar a descrição dos verbetes produzidos para Conservapedia e para RationalWiki, vale comparar o design das páginas iniciais anglófonas, pois a interface de ambas é muita parecida e remete à estrutura básica das páginas produzidas com o uso do software Wiki, o que as deixa, na verdade, iguais à Wikipedia, por exemplo, ao apresentarem barra lateral com menu à esquerda e caixas com informações espalhadas pelo centro. Essas informações não são fixas, isto é, costumam ser atualizadas e alteradas constantemente. A estrutura é tão similar entre os sites que os recursos se repetem e todas dispõem de links para mudanças recentes, artigos aleatórios, versão adaptada para impressão, páginas novas e seção de ajuda para novatos.

Vale dizer que há um Livro de Estilo, um manual para que colaboradores postem ou organizem verbetes na Wikipedia. Embora a formatação ali descrita não seja obrigatória, ela se faz valer pelo argumento apresentado de que a manutenção da identidade, tanto na organização do design pelo uso da plataforma Wiki, quanto de recursos expressivos da linguagem, auxiliam o reconhecimento mais imediato da página pelos leitores.

Seguindo o princípio da navalha de Occam, parece que a resposta da razão por que Conservapedia e RationalWiki escolherem manter o formato original é a mais simples: o design funciona porque a interação com o usuário, essencial para o sucesso de uma página, tira proveito da familiaridade. Isto é, quanto mais facilmente um site for reconhecido como Wiki, maior será a propensão de que o leitor assuma o papel de colaborador direto - e nada mais prático para isso do que deixar as páginas idênticas à Wikipedia, embora o software Wiki permita algumas alterações que poderiam dar uma identidade diferenciada tanto para a Conservapedia quanto para a RationalWiki. Observese, na página seguinte, o design semelhante ao das duas.

Diante da imensa variedade de modelos de sites no universo digital contemporâneo, resta o fato curioso de duas enciclopédias formadas por comunidades discursivas tão distantes não demonstrarem qualquer diferença em seu design. Porém, para este trabalho, o que importa é que a própria apresentação dos verbetes nessas enciclopédias não é alterado, ou seja, dificilmente, o design das páginas estaria de algum modo interferindo na estrutura sociocomunicativa desses textos, até porque também a enciclopédia analógica apresenta um design que relaciona imagens junto aos verbetes, como mapas, tabelas, fotos, gráficos, infográficos, como pode ser visto na figura 2 a seguir:

\subsection{A ESTRUTURA GERAL DOS VERBETES NA CONSERVAPEDIA E NA RATIONALWIKI}

Após a análise com foco no contexto geral em que são produzidos os verbetes, isto é, observando a organização dos suportes em que eles ocorrem, enciclopédias digitais e analógicas, agora as lentes são dirigidas para a estrutura do próprio verbete. Para isso, será apresentada uma comparação entre as duas enciclopédias no que tange a um mesmo artigo. Dessa forma, foram separados os verbetes da Conservapedia e da RationalWiki sobre aborto, dado que as explícitas diferenças entre as comunidades discursivas quanto ao tema servem aos propósitos da análise. 
Figura 1 - <Conservapedia.com> (topo) e <RationalWiki.org>: equivalência visual Figure1: <Conservapedia.com > (top) and <RationalWiki.org>: visual equivalence

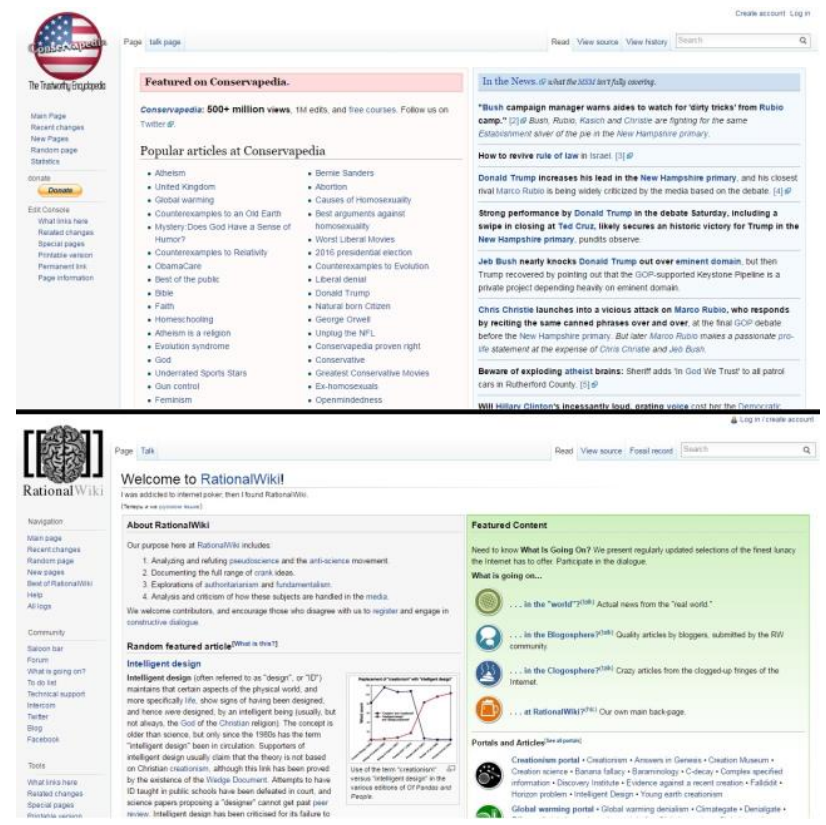

Fonte: Captura de tela das páginas iniciais de Conservapedia e RationalWiki.

Figura 2 - Exemplo de diagramação de enciclopédia tradicional impressa Figure 2 - Examples of a traditional print encyclopedia's design

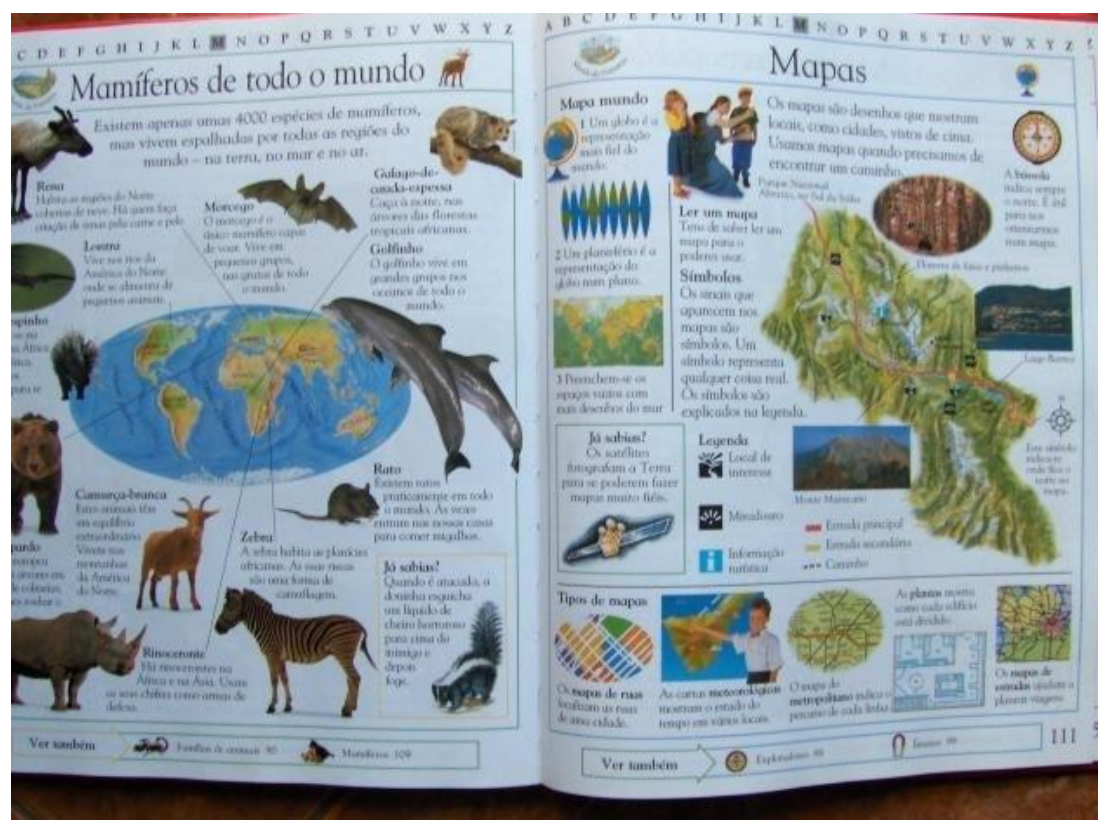

Fonte: <https://goo.gl/9V6i2o>. Acesso em nov. 2016. 
Diante de duas abordagens para o mesmo verbete, percebe-se que ambas as páginas apresentam a diagramação típica de conteúdo elaborado para a Wikipedia, isto é, texto escrito somado a recursos visuais que auxiliam a navegação e dispõem de informações diretas por meio de quadros e tabelas. Tanto na Conservapedia quanto na RationalWiki, um texto sucinto - se comparado à totalidade do artigo - precede os pontos aprofundados nas seções. Além disso, há uma caixa de conteúdos em cada um dos artigos, a qual serve como resumo dos tópicos, listando as seções dos verbetes, e se localiza após o texto inicial deles. No caso da RationalWiki, uma outra caixa foi incluída à direita da página, agrupando temas relacionados ao assunto aborto - uma prática comum da Wikipedia. Já na Conservapedia, a imagem de um feto pode ser vista logo no topo da página. Ambas contêm imagens ao longo do verbete.

Esse texto inicial sugere outro traço interessante no que diz respeito à comparação. Os dois artigos - e isso muito se repete nas duas enciclopédias, assim como acontece nas impressas - iniciam os verbetes com as informações mais notáveis sobre o assunto e seus dados gerais. Após a caixa de conteúdos, com hiperlinks para as seções da página, o texto inteiro se desenrola - é nesse segundo momento que o artigo se aprofunda de fato. Novamente, trata-se de outro padrão estrutural típico empregado pela Wikipedia: sem prestar atenção, pode-se levar um tempo navegando pela Conservapedia ou pela RationalWiki até entender que não se trata da Wikipedia, pois além da identificação visual dos sites em si, a estrutura dos verbetes segue um padrão claro. Em outro ponto comum, nota-se que as duas enciclopédias não poupam o uso de hiperlinks, conforme o esperado para suas mídias. Qual a Wikipedia, é padrão transformar qualquer ano, país e pessoa em hiperlink para outro artigo, mesmo que o artigo de destino ainda nem exista - e nesse caso, ao invés de azul, o link aparece na cor vermelha. Vale destacar que essa estrutura também é a que orienta a informação em rede nas enciclopédias tradicionais e, geralmente, inclusive a cor azul é a usada para destacar a palavra que tem mais informações indicadas em outras páginas.

Seja pelos artigos sobre aborto, seja por verbetes biográficos ou de assuntos variados, não se observam discrepâncias estruturais notáveis entre a Conservapedia e a RationalWiki: do conservadorismo ao ceticismo racional, não há nada novo sob o sol, muito menos sob a formatação dos verbetes em sua configuração geral. Basta verificar que enciclopédias escolares geralmente são mais ilustrativas, como o exemplo apresentado anteriormente, ou seja, a depender da temática da enciclopédia, seus verbetes apresentarão maior ou menor relação entre linguagem verbal e não verbal.

\subsection{A QUESTÃO DA MODALIZAÇÃO}

Ajustando ainda mais o foco de análise, a investigação recai sobre a regularidade linguística ao verificar a ocorrência de elementos mais finos da macroestrutura do texto, ou seja, se propõe a comparar os modalizadores empregados nos verbetes das duas enciclopédias de sistema Wiki com aqueles que a literatura linguística diz que fazem parte da organização do tipo textual que sustenta esses gêneros nas enciclopédias tradicionais. 
Sobre isso, Schneuwly e Dolz (2004), por exemplo, elencam os verbetes como pertencentes à tipologia da exposição, pois essa seria a capacidade de linguagem dominante para as ações de transmissão e construção de saberes. Porém, Travaglia (2007b) defende que pode ocorrer cruzamento de tipos nos gêneros e que o argumentativo frequentemente se cruza com o dissertativo, e isso tem levado, conforme o autor, muitos estudiosos a confundir os dois, ou a propor o tipo expositivo, quando se tem apenas a dissertação. E esse tipo, isto é, dissertativo é a categoria do texto do conhecer abstraído do tempo e do espaço, no qual o que

importa como informação são as entidades, as proposições sobre elas e as relações entre estas proposições, sobretudo as de condicionalidade, causa/consequência, de oposição (ou contrajunção), as de adição (ou conjunção), de disjunção, de especificação, inclusive exemplificação, de ampliação, de comprovação, etc. (TRAVAGLIA, 2007a, p. 43).

Como este trabalho segue a análise dos tipelementos propostos por esse autor, o verbete, então, será considerado como exemplar de gênero cujo tipo essencial é dissertativo e não expositivo, pelos motivos já descritos.

Desse modo, as características propostas para esse tipo deveriam fazer parte da regularidade linguística do verbete, e, como defendido aqui, até o momento com base nas questões sobre superestrutura, a macroestrutura também não apresentaria diferença ao se comparar os textos das enciclopédias de Web e as impressas, ou seja, não haveria o surgimento de novo gênero nas Wikis, nem mesmo de espécie de verbete. Então, é importante verificar se as características elencadas por Travaglia (2007a) aparecem nos verbetes de ambos os suportes. Em síntese, o que o pesquisador destaca como responsável pela textualização do tipo dissertativo é a ocorrência de maior número de verbos gramaticais, sobretudo os auxiliares modais, e a grande presença tanto de verbos dinâmicos quanto estáticos, bem como de verbos enunciativos de pensar. Com relação ao tempo verbal, Travaglia (2007a) nota que aparecem todos os tempos verbais (categoria), mas a predominância é do onitemporal, tendo em vista a característica da dissertação de apresentar ideias vistas como válidas para todos os tempos, o conhecer abstraído do tempo. A marcação cronológica dos fatos enunciados parece ser característica do texto dissertativo. Sobre a aspectualidade, o estudioso diz ser recorrente o aspecto imperfectivo, começado, o cursivo e os de duração ilimitada (indeterminado e habitual), já que pretendem apresentar fatos como válidos para todos os tempos.

É preciso dizer que a análise dos dados dos verbetes aqui avaliados parece sustentar todas essas características, ou seja, não se diferenciam do tipo dissertativo que sustenta os verbetes tradicionais. No entanto, a característica mais importante para este estudo e que foi investigada com maior profundidade diz respeito ao fato de que, para Travaglia (2007a), no tipo dissertativo, as modalidades que ocorrem com maior frequência são a certeza e a possibilidade.

Para investigar essa questão, retoma-se a descrição de Castilho (2010) para observar que, no verbete sobre aborto da Conservapedia, os modalizadores epistêmicos, aqueles que denotam juízo de valor, ocorrem mais com o uso da negação da proposição do que com expressões adverbiais. Também nota-se que a negação acompanha, em quase todas as ocorrências, a modalização deôntica, aquela que se apropria do sentido de obrigação, dever, principalmente com os verbos can como permissão, should como conselho. Note- 
se que não houve ocorrência de must (obrigação) ou may (permissão); este último teve apenas uma ocorrência como possibilidade. Seguem as sentenças:

1) ...and may indicate pressure to abort comes not so much from husbands now as other relationships

2) Liberals believe that the unborn child has no right to life.

3) ... and the mother who can never forget the loss she caused...

4) A right to privacy would not permit the taking of life when that life is inconvenient.

5) Saying one can't criticize a woman's choice to murder her children is like saying one can't criticize the president without being the president...

6) ...for once it is we should not take its life lightly...

Mais raras do que as ocorrências de modalização epistêmica negativa, as afirmativas registradas no verbete da Conservapedia foram:

7) ...often causing fetal pain.

8) These are 60 thousand abortions each year that are clearly murder...

9) Just $25 \%$ believe abortion should be legal under all circumstances, and an additional $13 \%$ believe it should be legal under most circumstances. Most Americans believe abortion should usually be illegal save in rare cases.

Observe-se que em 2 e 9 também ocorre o verbo believe, o qual pode ser encaixado no terceiro grupo proposto por Castilho (2010), os modalizadores discursivos. Porém, esses usos estão se dando de modo a colocar a atitude proposicional de "crença" no discurso não do produtor do verbete, mas da opinião pública. Além da presença desse verbo, mais três ocorrências se destacaram para essa categoria de modalização:

10) A growing body of evidence increasingly suggests that abortion is linked to Breast Cancer.

11) ...women's health has dramatically improved there due to fewer abortions.

12) Rape or life of the mother are extremely rare circumstances accounting for less than $1 \%$ of all abortions,...

Os dados da RationalWiki mostram um número maior de ocorrências de modalização epistêmica pelo emprego de advérbios. Diferentes da Conservapedia, a modalização dessa categoria por meio da negação só teve uma ocorrência, em $\mathbf{8}$, justamente a que também apresenta modalização deôntica com o uso do verbo could (poder). Não foram encontradas ocorrências de modalizadores discursivos. Seguem as sentenças do verbete:

a) ...focuses on this debate about the legality of induced abortion, specifically within modern "Western" culture.

b) In most parts of the world these issues continue to be debated, especially over what specific legal limits should be placed on abortion throughout the...

c) The debate about the legality of abortion generally divides into two camps. 
d) ...are most often called "pro-choice", and are often called "anti-life" by their opposition.

e) It is likely that the desire to terminate a pregnancy has been around as long as women have understood the cause of pregnancy...

f) It is known that every culture studied has some form of abortifacient, or at least something they believed to be and accepted as an abortifacient.

g) The morality and legality of abortion are hotly contested issues, certainly within the United States but also across many countries of the world. Generally, debate will focus...

h) If this was the case, then the act of causing a miscarriage could not be construed as 'murder'.

É possível notar que a Conservapedia apresenta mais ocorrências de modalização do que a RationalWiki, provavelmente por isso, o leitor, diante do verbete da primeira, tem uma sensação maior de defesa de um ponto de vista, lembrando que, aliás, esse é o propósito da enciclopédia. Analogamente, de modo invertido, para atender ao objetivo de cientificidade, a RationalWiki apresenta um número menor tanto de ocorrências quanto de categoria de modalização. Mas a questão é: essas organizações se dão pela produção de um gênero novo ou uma espécie nova do gênero verbete?

Para responder a essa pergunta, é válido rever a proposta de Travaglia (2007a) sobre o tipo dissertativo, considerado aqui como base para o gênero verbete de enciclopédia. $\mathrm{O}$ autor afirma que em um texto do conhecer conceitual predominam as modalidades da certeza $(83,7 \%)$, da possibilidade (10,37\%) - entendidos aqui, a partir de Castilho (2010), como pertencentes, respectivamente, às categorias epistêmica e deôntica. Exatamente a categoria epistêmica foi a que mais ocorreu em ambos os verbetes e, justamente, a deôntica apresentou-se em segundo lugar, ainda que com maior presença na Conservapedia do que na RationalWiki. Travaglia (2007b) ainda observa a ocorrência de modalização da probabilidade $(4,08 \%)$ no tipo dissertativo, a qual também teve baixa presença nos verbetes aqui analisados.

Ou seja, embora as duas enciclopédias tenham objetivos fortemente aplicados para a apresentação de seus conteúdos, ao elaborar seus verbetes parece haver uma preocupação em limitar a modalização discursiva, assim como acontece nos verbetes tradicionais. Talvez isso se dê porque as enciclopédias de Wiki, embora abertas para colaboração, editam seus verbetes seguindo normas que regem o andamento das publicações por meio do Guia de Estilo. A Wikipedia, possivelmente seguida pelas outras não apenas em seu design gráfico, mas também no padrão da organização retórica, propõe a uniformização dos verbetes, em termos de forma e estilo, recomendando, por exemplo, que se evite a utilização de termos especializados ou palavras rebuscadas. Pode ser que, no momento de edição dos verbetes, ainda prevaleça o protótipo de macroestrutura dos verbetes tradicionais e isso os leve a cuidar, intuitivamente, do emprego de modalizadores. Fato é que os verbetes não fogem da organização linguística tradicional desse gênero mesmo em enciclopédias Wiki com objetivos tão opostos, portanto, ainda é preciso mais investigações para poder afirmar que os verbetes elaborados para suporte são novos, como proposto por autores aqui apresentados. 
Tomando os pressupostos de Araújo (2016), pode-se acrescentar à conclusão da análise aqui conduzida o fato de que, no continuum entre reelaboração estandardizada e emergente, os suportes dos verbetes de Web não se desvencilham do estilo proposto para a primeira enciclopédia desse modelo: a Wikipedia. Todas parecem manter a referência dela para organizar o design da página, as suas funcionalidades e as subdivisões textuais do próprio verbete. Mais que isso, tal design relaciona linguagem verbal e não verbal tanto quanto a diagramação dos suportes tradicionais impressos, ou seja, mantém um remix existente no gênero analógico, a depender da necessidade da complementaridade entre linguagens diferentes para ampliar os sentidos do tema.

A segunda questão observada nos verbetes sustentados por Wiki é a de que o uso de hiperlink não parece ser característica suficiente para determinar o surgimento de um gênero novo nesse caso - ideia defendida por Lima (2009) -, visto que a informação organizada em rede também existe nas enciclopédias impressas a partir de palavras, expressões, datas nomes, como indicadores para referenciação de busca complementar. A diferença está no sistema de busca automático, mas não na textualização dos verbetes. Ou seja, não parece ser possível defender uma atualização emergente para os verbetes Wiki graças ao uso de hiperlink, visto que no continuum desse gênero já havia nos originais analógicos certas formas de informação em rede.

Uma última proposição, ainda, para corroborar a hipótese de que não há surgimento de verbete novo com a criação de enciclopédias digitais, e nem mesmo uma nova espécie desse gênero, mas apenas uma atualização estandardizada, vem da análise da ocorrência de modalizadores nesses textos, a qual indica que a regularidade linguística no uso de elementos responsáveis pela modalização se mantém nos exemplares aqui investigados, ou seja, a estrutura é a mesma entre os verbetes de Web e os analógicos, não sendo possível observar ainda sequer alteração no propósito comunicacional.

Assim, ao se considerar também a proposta de Araújo (2016), a manipulação de padrões do gênero verbete Wiki para atuar, interagir por meio da Web, parece estar ainda muito próxima do gênero analógico original no movimento de formação em um continuum discursivo, tendendo à estandardização, visto que sequer um remix se dá de outra forma na organização textual, muito menos se observa mashups, nem da super nem da macroestrutura. Com esses apontamentos, espera-se que esses resultados acrescentem alguns pontos à discussão dos gêneros digitais, instigando a proposição de novos questionamentos para o estudo, ressaltando que este é um trabalho inicial sobre o tema.

\section{REFERÊNCIAS}

ARAÚJO, J. Reelaboração de gêneros em redes sociais. In: ARAÚJO, J.; LEFFA, V. (Org.) Redes sociais e ensino de línguas: o que temos de aprender? São Paulo: Parábola Editorial, 2016.

BAKHTIN, M. M. Estética da criação verbal. São Paulo, Martins Fontes, 2011[1979].

CASTILHO, A. T.; CASTILHO, C.M.M. Advérbios modalizadores. In: ILARI, R.: Gramática do português falado. Vol. 2. São Paulo, Unicamp, 1993. p. 213-260.

CASTILHO, A. T. Nova Gramática do português brasileiro. São Paulo: Contexto, 2010. 
COHEN, N. Wikipedia vs. the Small Screen. New York Times, Nova York, p. B14, fev. 2014.

CONSERVAPEDIA. Abortion. Disponível em:

<http://www.conservapedia.com/index.php?title=Abortion\&oldid=1191931>. Acesso em: abr. de 2016.

COSTA, R.R. A TV na Web: percursos da reelaboração de gêneros audiovisuais na era da transmídia. Dissertação de mestrado. Fortaleza: PPGL-UFC.

DENNIS, M. A. Encyclopaedia Britannica [versão eletrônica]. Encyclopaedia Britannica Inc. Disponível em: 〈http://www.britannica.com/topic/wiki>. Acesso em: jan. 2016.

DIONÍSIO, A. P.. Verbetes: um gênero além do dicionário. In: DIONÍSIO, A. P.; MACHADO, A. R.; BEZERRA, M. A. (Org.). Gêneros textuais e ensino. 4. ed. Rio de Janeiro: Lucerna, 2005. p. 125-137.

LIMA, V.W. Gênero e colaboração: a construção do verbete da Wikipedia. (2009). Disponível em: <https://www.ufpe.br/nehte/hipertexto2009/anais/g-1/genero-e-colaboracao.pdf>. Acesso em 21 de abril de 2016.

MARCUSCHI, L. A. Gêneros textuais emergentes no contexto da tecnologia digital. In: MARCUSCHI, L.A.; XAVIER, A. C. (Org.). Hipertexto e gêneros digitais: novas formas de construção de sentido. São Paulo: Cortez, 2010.

MCCARTHY, T. Encyclopedia Britannica halts print publication after 244 years. The Guardian [internet], Londres, mar. 2012. Disponível em

<http://www.theguardian.com/books/2012/mar/13/encyclopedia-britannica-halts-print-publication>. Acesso em: abr. 2015.

MILLER, C. Genre as social action. In: FREEDMAN, Aviva; MEDWAY, Peter, (Org.). Genre and the new rhetoric. London: Taylor \& Francis, 1994. p. 23-42.

RATIONALWIKI. Abortion. Disponível em:

<http://rationalwiki.org/w/index.php?title=Abortion\&oldid=1642188>. Acesso em abril de 2016.

SCHNEUWLY, B; DOLZ, J. Gêneros orais e escritos na escola. Trad. e org. Roxane Rojo e Glaís Sales Cordeiro. Campinas, SP: Mercado de Letras, 2004

TRAVAGLIA, L. C. A caracterização de categorias de texto: tipos, gêneros e espécies. Revista Alfa, São Paulo, v. 51, n. 1, p. 39-79, 2007a.

Das relações possíveis entre tipos na composição de gêneros. In: SIMPÓSIO

INTERNACIONAL DE ESTUDOS DE GÊNEROS TEXTUAIS, 4., 2007, Tubarão. Anais... TubarãoSC: UNISUL, 2007b. p. 1297-1306.

VAN DIJK, T. A., KINTSCH, W. Strategies of discourse comprehension. New York: Academic Press, 1983.

XAVIER, A. C. Leitura, texto e hipertexto. In: MARCUSCHI, L. A; XAVIER, A. C. (Org.). Hipertexto e gêneros digitais: novas formas de construção de sentido. São Paulo: Cortez, 2010.

A era do hipertexto: linguagem e tecnologia. Pipa Comunicação, 2013.

WIKIPEDIA. Página do projeto: enciclopédia. Disponível em:

<https://pt.wikipedia.org/wiki/Enciclop\%C3\%A9dia>. Acesso em: abr. 2016.

Recebido em:02/05/17. Aprovado em: 22/02/18.

Title: Textualization of encyclopedic entries in Wiki systems

Authors: Rossana Aparecida Finau; Mateus Lourenço Reibeirete

Abstract: This article aims to analyze textualization in entries of Wiki encyclopedias in order to find out if they form a new genre or a new kind of genre, from the perspective of tipelementos proposed by Travaglia (2007a, 2007b), or whether they keep their main characteristics from paper encyclopedias. Thereunto, from the perspective of a qualitative research, two articles from different Wikis are compared from their superstructure organization to their macrostructure, taking the occurrence of modalization as specific data of linguistic regularity. To describe modalization, a link with the tipelementos theory is proposed. Analysis then parts from a general focus, following Araújo's (2016) approach to the re-elaboration of new genres in digital media, from the genre's formation context to its intern structure. We observed there are not enough differences between entries to the point of arguing for the emergence of a new entry genre merely because of its digital medium.

Keywords: Technology. Hypertext. Wiki. Articles. Tipelementos. 
Título: Textualización de entradas enciclopédicas en sistemas Wiki

Autores: Rossana Aparecida Finau; Mateus Lourenço Reibeirete

Resumen: Este artículo tiene el objetivo de analizar la textualización de entradas de enciclopedias Wiki para verificar se son resultantes de la creación de un nuevo género, una innovación que genera la emergencia de nueva especie - en la perspectiva de tipelementos de Travaglia (2007a, 2007b) - o si mantienen las características tradicionales de los textos imprimidos. Para ello, en una investigación cualitativa, dos entradas de enciclopedias de la Web son comparadas desde su organización de superestructura hasta la macro estructura, adoptando como dato más específico de las regularidades lingüísticas la ocurrencia de modalizadores en entradas. El análisis parte de un foco más general, siguiendo la orientación de Araújo (2016) para análisis de reelaboración de géneros en medios de comunicación digitales, comprobando el contexto de formación del género. Se observa que no hay diferencias suficientes entre la textualización de los ejemplares a punto de defender el surgimiento de un nuevo género de entrada por ser presentado de modo digital.

Palabras-clave: Tecnología. Hipertexto. Wiki. Entrada. Tipelementos.

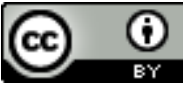

Este texto está licenciado com uma Licença Creative Commons Atribuição 4.0 Internacional. 